This item was submitted to Loughborough's Research Repository by the author.

Items in Figshare are protected by copyright, with all rights reserved, unless otherwise indicated.

\title{
Shear enhanced microfiltration and rejection of crude oil drops through a slotted pore membrane including migration velocities
}

PLEASE CITE THE PUBLISHED VERSION

http://dx.doi.org/10.1016/j.memsci.2012.06.040

PUBLISHER

(C) Elsevier

VERSION

AM (Accepted Manuscript)

LICENCE

CC BY-NC-ND 4.0

\section{REPOSITORY RECORD}

Ullah, Asmat, R.G. Holdich, M. Naeem, and Victor Starov. 2012. "Shear Enhanced Microfiltration and Rejection of Crude Oil Drops Through a Slotted Pore Membrane Including Migration Velocities". figshare. https://hdl.handle.net/2134/10403. 
This item was submitted to Loughborough's Institutional Repository (https://dspace.lboro.ac.uk/) by the author and is made available under the following Creative Commons Licence conditions.

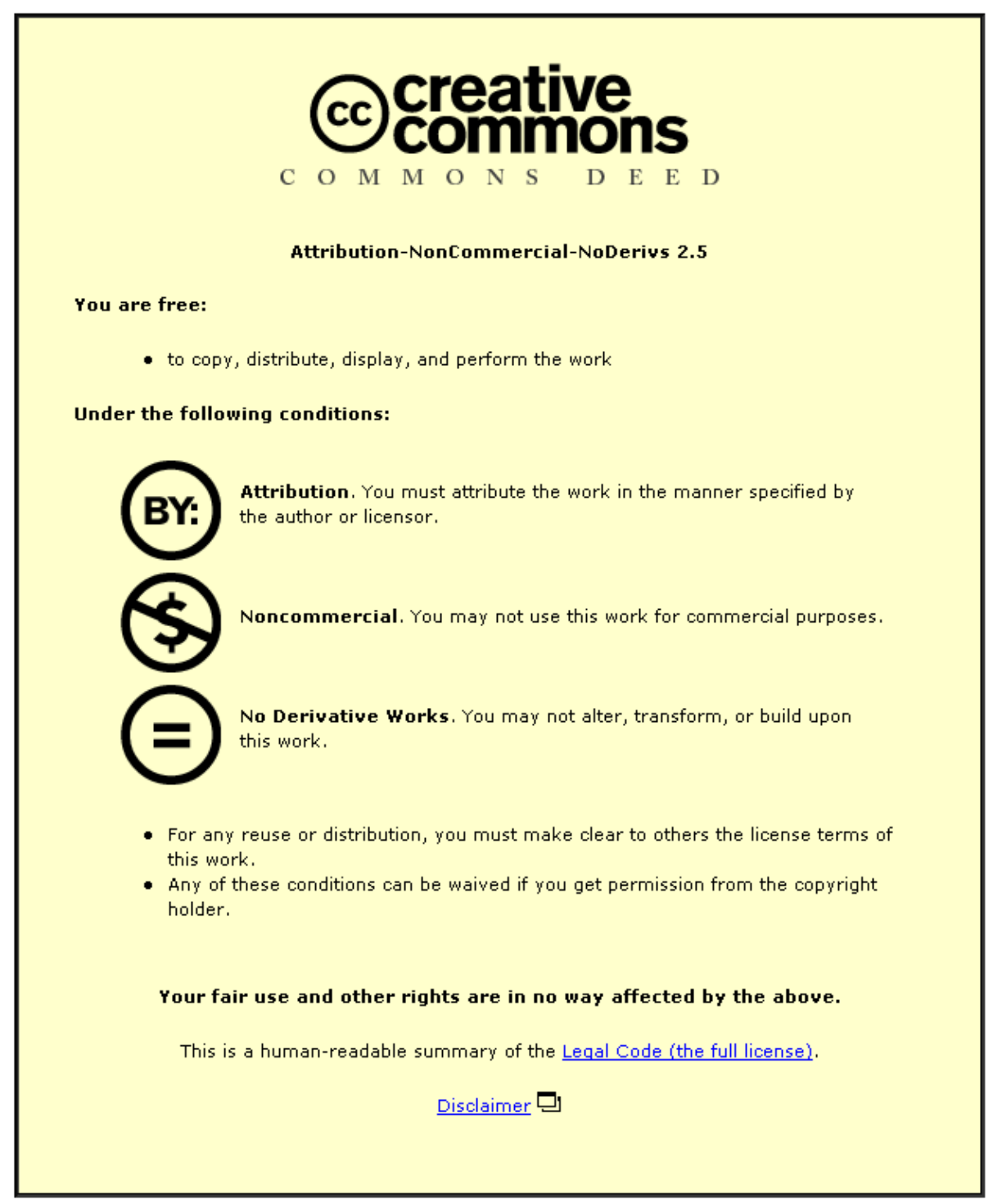

For the full text of this licence, please go to: http://creativecommons.org/licenses/by-nc-nd/2.5/ 
Shear enhanced microfiltration and rejection of crude oil droplets through a slotted pore membrane including migration velocities

\author{
A. Ullah ${ }^{\star}, a, b$, R.G. Holdich ${ }^{a}$, M. Naeem ${ }^{c}$, V.M. Starov ${ }^{a}$ \\ *To whom correspondence should be addressed: A.Ullah@lboro.ac.uk \\ aDepartment of Chemical Engineering Loughborough University, \\ Leicestershire LE11 3TU, UK \\ ${ }^{\mathrm{b}}$ Department of Chemical Engineering KPK UET Peshawar Pakistan \\ ${ }^{\mathrm{C} D e p a r t m e n t}$ of Chemistry AWKUM Mardan Pakistan.
}

\begin{abstract}
Shear enhanced microfiltration of crude oil/water emulsion is investigated and the effect of an applied shear rate on the rejection of droplets by the membrane is reported. Applying vibration provides shear rate at the membrane surface leading to shear-induced migration and an inertial lift of drops/particles. Both phenomena tend to move the droplets away from the membrane surface. The shear-induced migration and inertial lift increase with increasing of the shear rate. A mathematical model is presented to account for the presence of both phenomena. The developed model is used for theoretical prediction of $100 \%$ cut-off of crude oil droplets by the membrane with, and with-out, vibration applied. A satisfactory agreement of the model predictions with experimental data shows that the model can be successfully used for a theoretical prediction of $100 \%$ cut-off of droplets by slotted pore membranes. Rejection of droplets increased with applying shear rate: at 8000 $\mathrm{s}^{-1}$ shear rate and $200 \mathrm{I} \mathrm{m}^{-2} \mathrm{hr}^{-1}$ flux rate 3 to $4 \mu \mathrm{m}$ radius droplets were almost
\end{abstract}


completely rejected reducing $400 \mathrm{ppm}$ of crude in the feed to $7 \mathrm{ppm}$ in the permeate.

Keywords: Crude oil, vibrations imposed, shear enhanced microfiltration, rejection.

\section{Introduction}

Dispersed oil droplets in water represent an environmental problem and are associated with a number of chemical industries, especially with offshore oil production. Produced Water is the water from oil reservoirs and it contains poly-dispersed droplets of crude oil. Produced Water can be disposed of by re-injecting into oil fields, however, frequently it is discharged directly into the sea. The quantities of Produced Water discharged into the sea per installation ranges from 860 to $2700 \mathrm{~m}^{3}$ day $^{-1}$ [1]. This poses a threat to aquatic life and this is the reason why the amount of oil in Produced Water that can be discharged into the sea is limited to $30 \mathrm{mg} \mathrm{l}^{-1}$ [2]. Hydrocyclones can be used as a secondary separator, after gravity sedimentation, for removal of oil content from the Produced Water. However, hydrocyclones are mainly efficient for droplets above $20 \mu \mathrm{m}$ in size and for light oil drops [3; 4].

Various membrane separation techniques can be used for the removal of oil droplets from water. Ultrafiltration is useful with low oil content, but has permeate flux rates lower than $100 \mathrm{I} \mathrm{m}^{-2} \mathrm{hr}^{-1}$ which was found too low to be commercially attractive offshore [5; 6]. For Produced Water microfiltration has been studied by various researchers [7-11]. Higher flux rates (above $100 \mathrm{I} \mathrm{m}^{-2}$ $\mathrm{hr}^{-1}$ ) were achieved. Permeate flux rates in microfiltration depend on droplet size and type of membrane used. However, particles/droplets can be retained inside the membrane $[12 ; 13]$ if filters/membranes with complex and torturous 
internal structures are used. The latter can cause severe fouling of the membrane used.

Recently, developments in membrane pore geometry have attracted great interest. Membranes with circular pores are often investigated [14]. In general, a membrane with smaller pore size $(2 \mu \mathrm{m})$ has higher efficiency for separating oil droplets up to $10 \mu \mathrm{m}$ compared to a $5 \mu \mathrm{m}$ membrane [14] using the same trans-membrane pressure. However, even better separation of oil droplets was achieved with slotted pore-filters under lower trans-membrane pressure [13]. Different mechanisms govern the droplet passing through the membrane when circular or slotted pores geometries are used. When circular pore are used the trans-membrane pressure governs the droplets passing through the membrane into the permeate. In the case of slotted pores the drag force around the droplets induced by the motion of the fluid into the permeate is more important and is mostly responsible for the droplets passing through the membrane [2].

Rotating, or vibrating, the membrane results in the creation of shear on the membrane surface [18]. In cross-flow filtration the shear rate over the membrane surface is applied by fluid flow at a high velocity [19]. While in shear enhanced filtration by vibrating the membrane shear is created even at a low fluid velocity [20]. Trans-membrane pressure reduced 4 times during microfiltration of oil/water emulsion by applying $8100 \mathrm{~s}^{-1}$ shear rate to the surface of the membrane [21]. Higher permeate flux rate has also been achieved by controlling the fouling of the membrane with the vibration of the membrane during filtration of yeast suspensions [22]. Permeate flux rate was found to be function of vibrational frequency and amplitude at which the 
membrane was vibrated [23]. Separation of deforming droplets is still a challenge for researchers. During filtration the initially spherical shape of the oil droplets deform and the degree of deformation depends upon the geometry of the membrane pores. In the following work the influence of membrane vibration, and resulting shear rate, on rejection of deformable oil droplets through a microfiltration slit pore membrane is investigated. A theoretical model is proposed to predict the rejection as a function of applied shear rate.

\section{Theory}

Static force $\left(F_{c}\right)$ is the force responsible for the rejection of drops through the membrane when reach to the surface of the membrane and can be expressed as follows: [24],

$$
F_{c x}=+2 \sin \frac{\alpha}{2} \times 2 \pi \sigma R_{s p}^{2}\left(+\frac{3 \lambda^{3}+\frac{\arccos \lambda^{3}}{\sqrt{1-\lambda^{6}}}\left(1-4 \lambda^{6}\right)}{\lambda^{2}\left(1-\lambda^{6}\right)}-2 \lambda\right)
$$

Where $\sigma$ is interfacial tension between oil/water, $R_{s p}$ is the radius of the drop, and $h$ is the half width of slot of the membrane and $\lambda=\frac{h}{R_{\text {ell }}}$.

The drag force exerted on a sphere moving between two pates is given in [25] as:

$$
F_{d}=k_{w} 6 \pi n R_{s p} U
$$

where $k_{w}$ is a wall correction factor, $\eta$ is viscosity of the fluid, $R_{s p}$ is the radius of the spherical droplet and $U$ is the velocity of the fluid. The droplet is under steady state conditions inside the pore, when $F_{c x}$ becomes equal to $F_{d}$ and 
the droplets will be captured in this position. The droplet will deform and will pass through the membrane when $F_{d}>F_{c x}$ and it will be rejected by the membrane in the case of $F_{d}<F_{c x}$ [24].

When vibration is imposed then the latter results in an applied shear rate. The latter results in a shear-induced migration velocity, $v_{s h m}$, directed away from the membrane surface and inertial lift velocity, $v_{i f}$, which is also directed away from the membrane surface. As a result initial droplet velocity in a vicinity of the membrane surface is decrease by $v_{s h m}+v_{i f}$. Shear-induced migration velocity of a single droplet away from the membrane surface is given [26]:

$v_{s h m}=\beta C_{a} \dot{\gamma} R_{s p} \frac{R_{s p}{ }^{2}}{y^{2}}$,

where $v_{s h m}$ is shear-induced migration velocity, $\beta$ is a numerical coefficient and its value is equal to 0.6 [26], $\dot{\gamma}$ is shear rate, $y$ is the distance from membrane surface to the centre of the droplet [27]; $C_{a}=\eta \dot{\gamma} R_{s p} \frac{1}{\sigma}$ is capillary number, where $\eta$ is viscosity of the continuous phase. Combination of the latter expression and Eq. (3) results in a final equation for a shear-induced migration velocity of a single droplet away from the membrane surface:

$v_{s h m}=0.6 \eta \dot{\gamma}^{2} \frac{R_{s p}^{4}}{\sigma y^{2}}$

Migration velocity of a droplet due to inertial lift, $v_{i f}$, was deduced in [28]:

$v_{i f}=\frac{\rho_{f} \dot{\gamma}^{2} R_{s p}^{4}}{16 \eta y}$

where $\rho_{f}$ is density of the fluid and $\eta$ is viscosity of the fluid. 
Shear-induced migration and inertial lift velocity are calculated below according to Eqs (4) and (5). Both velocities are directed oppositely to a migration, $v_{0}$, caused by the flowing liquid.

The latter consideration shows that droplets reach the surface of the membrane with a velocity $\mathrm{v}$, which is lower than the velocity of the flowing liquid:

$v=v_{0}-v_{s h m}-v_{i f}=v_{0}-0.6 \eta \dot{\gamma}^{2} \frac{R_{s p}{ }^{4}}{\sigma R_{s p}^{2}}-\frac{\rho_{f} \dot{\gamma}^{2} R_{s p}^{4}}{16 \eta R_{s p}}=v_{0}-0.6 \eta \dot{\gamma}^{2} \frac{R_{s p}{ }^{2}}{\sigma}-\frac{\rho_{f} \dot{\gamma}^{2} R_{s p}^{3}}{16 \eta}$.

Note the latter velocity was calculated when the droplet reached the membrane surface. The latter expression is used below for comparison with experimental data. Let make a simple analysis of the latter equation before using it.

If velocity of the droplet on the membrane surface becomes negative then the droplet cannot reach the membrane and will be transferred from the membrane. For a droplet of fixed radius $R_{s p}$ the latter will happen if the applied shear rate is above a critical shear rate $\dot{\gamma}>\dot{\gamma}_{c r}$, where

$$
\dot{\gamma}_{c r}=\sqrt{\frac{v_{0}}{0.6 \eta \frac{R_{s p}{ }^{2}}{\sigma}+\frac{\rho_{f} R_{s p}^{3}}{16 \eta}}} .
$$

The latter is a decreasing function of the droplet radius, $R_{s p}$. From other hand if we fix the applied shear rate then all particles with a radius bigger than $R_{s p}>R_{s p, c r}$ will not be able to reach the membrane surface and will be transfer from the surface. According to our experimental conditions $0.6 \eta \frac{R_{s p}{ }^{2}}{\sigma}<<\frac{\rho_{f} R_{s p}^{3}}{16 \eta}$ and can be neglected. Hence, 
$R_{s p, c r}=\sqrt[3]{\frac{v_{o}}{\dot{\gamma}}\left(\frac{1}{\frac{\rho_{f}}{16 \eta}}\right)}$.

According to Eq (8) all drops bigger than $R_{s p, c r}$ will not reach the membrane surface.

Rejection of drops in the course of microfiltration process is a function of the filtration velocity, $v_{0}$. If the filtration velocity is smaller than the critical velocity $v_{0}<v_{0, c r}$ then all droplet of radius $R_{s p}$ will be transported away from the membrane surface, that is, $100 \%$ rejection will take place. Here,

$v_{0, c r}=0.6 \eta \dot{\gamma}^{2} \frac{R_{s p}{ }^{2}}{\sigma}+\frac{\rho_{f} \dot{\gamma}^{2} R_{s p}^{3}}{16 \eta}$.

The latter critical velocity increases with the droplet radius and applied shear rate.

If $v_{0}>v_{0, c r}$ then the procedure of calculation of the rejection is schematically shown in Fig. 2. At the fixed filtration velocity $v_{0}>v_{0, c r}$ the droplet will come to the membrane surface with a actual velocity lower than the initial filtration velocity $v_{0}$. The actual velocity will be $v_{0}-v_{0, c r}$. That is on the curve deduced for the absence of the applied shear rate we should shift by the value $v_{0, c r}$ to the left. Find the rejection corresponding to $v_{0}-v_{0, c r}$ and transfer the obtained value to the position $v_{0}$. The procedure is explained in Fig. 2 .

\section{Experimental}

\subsection{Materials}

Crude oil $\left(22^{\circ} \mathrm{API}\right)$ was supplied by North Sea operating companies. Permeate flux was sucked through the membrane by a peristaltic pump (RS 
440-515, UK). To measure trans-membrane pressure a sensitive pressure transducer (HCX001A60, Farnell, UK) was used. Filtration experiments were carried out with a $4 \mu \mathrm{m}$ slotted pore size see Fig. 3. (Micropore Technologies Ltd, UK). This is an unusual membrane filter design, as the pore is in the form of a slot and it has no internal tortuosity: it is similar to an industrial screen, but with a slot width of $4 \mu \mathrm{m}$ and a slot length of $400 \mu \mathrm{m}$. Shear rates were applied on the surface of membrane and membrane frequency was controlled through a voltage controller (Deltra eteckronika, 1464). For droplet size distribution and concentration determination a Coulter Multisier II (Coulter Counter, Coulter Electronics Ltd) was used. To avoid coalescence of droplets vegetable/water oil emulsion was gently stirred with a magnetic stirrer (Stuart Scientific, SM1, 13519, UK). The oil droplets were produced by a food blender (Kenwood manufacturing co Ltd Havant Hants, England). The membrane was cleaned with Ultrasil 11 and an ultrasonic bath (Fisher Scientific, FB 15046, Germany) was used to agitate the beaker containing Utrasil 11 water solution to clean the membrane.

\subsection{Filtration}

All filtration experiments were carried out using a $4 \mu \mathrm{m}$ slotted pore membrane attached to a vibrating arm activated by an electromechanical oscillator. A replaceable membrane was attached to the vibrating head using a hollow steel rod that provided both structural support as well as the permeate flow tube. Frequency and amplitude of membrane were controlled and were adjusted between 0 to $100 \mathrm{~Hz}$ and 0 to $10 \mathrm{~mm}$ respectively. Vibration is produced in the vertical direction that creates shear on the outer surface of the membrane. Emulsion feed was contained outside of the 
membrane and permeate was sucked, by a peristaltic pump (a positive displacement type of pump enabling almost constant flow rate conditions), and periodically collected in a measuring cylinder, trans-membrane pressure was recorded and the permeate returned to the feed tank. Trans-membrane pressure is defined here as the difference in pressures between the inside of the membrane and atmospheric pressure.

Filtration of crude oil/water emulsion was carried out with, and with-out, vibration of the membrane using various frequencies and flux rates. Before and after each run the membrane was cleaned with $2 \%$ Ultrasil 11 and hot $\left(50^{\circ} \mathrm{C}\right)$ filtered water. At different trans-membrane pressures various flux rates were obtained and compared with clean water flux rates at the respective trans-membrane pressures. Equilibrium conditions are those when transmembrane pressures and flux rates do not change with time. The membrane was vibrated vertically with various frequencies and, due to it, different intensities of shear rates were applied to the membrane. The effect of different intensities of shear rates were studied at the different flux rates using vibrating microfiltration rig see Fig. 4.

Shear rate is a function of velocity along the membrane surface [29], angular frequency $\omega(\omega=2 \times \pi \times f)$ and velocity amplitude where $f$ is linear frequency applied to the membrane. Shear rate at any instance of time, $t$, can be calculated as follows [29]:

$$
\dot{\gamma}(t)=v_{0} \sqrt{\frac{\omega}{2 v}}[\sin (\omega t)-\cos (\omega t)]
$$


where $v$ is kinematic viscosity of water $v_{0}$ is velocity amplitude. The maximum

value of the applied shear is equal to $\dot{\gamma}_{\max }=v_{0} \sqrt{\frac{\omega}{v}}$. It is adopted below and in our calculation above that the peak shear rate is the value that determines the filtration performance and just this peak value $\dot{\gamma}_{\max }$ is used as value $\dot{\gamma}$ in eq. (6).

\section{Results and discussions}

Droplets approach the membrane surface at the same velocity as the surrounding fluid velocity without shear rated imposed. It is assumed that droplets smaller than slot width pass through the membrane due to the drag force created by the fluid flow of the surrounding fluid. Static force $\left(F_{c x}\right)$ applied in opposite direction to drag force $\left(F_{d}\right)$ to the droplets bigger than slot width (see Fig. 1.). Droplets deform and pass through the membrane when drag force is higher than static force $\left(F_{d}>F_{c x}\right)$. The droplets are rejected by the membrane in the case of higher static force than the drag force $\left(F_{d}<F_{c x}\right)$. When shear rate is applied to the membrane shear-induced migration and inertial lift are created both directed away from the membrane. Migration velocities are a function of droplets size and applied shear rate (see Fig. 7.). Critical drops size would be the one above which drops do not reach the surface of the membrane, i.e. migration velocities due to shear rate is higher than the initial filtration velocity (Fig. 6.). As a result a rejection of droplets increased see Fig. 7. The experimental data presented in Fig. 7. are in a good agreement with the similar experimental investigations undertaken in [30]. Droplets reach the surface of the membrane if velocity of droplets due to 
filtration with the surrounding fluid is higher than the sum of shear-induced velocities and inertial lift velocity (see Eqs (7) and (8)). A relation between the static force and the applied drag force is responsible for the rejection or transport of the drop through the membrane once the droplet reaches the membrane surface.

Fig. 8. illustrates theoretical and experimental $100 \%$ cut-off of crude oil drops through a slotted pore membrane at various flux rates with and without applied shear rate. Drag force is strongly dependent on the fluid velocity around the drops, which (fluid velocity) is not affected by the applied shear rate: fluid velocity around the drops would be the same with and without shear rate applied. Without shear rate $100 \%$ cut-off would be when $F_{d} \leq F_{c x}$.

With the applied shear rate, theoretical $100 \%$ cut-off would be when drops not reach to the surface of the membrane due to migration velocities and can be obtain using Eq 8. Applying shear rate produced inertial lift and shear-induced migration both directed away from the membrane surface. Smaller number of drops would reach to the membrane surface when shear rate is applied. Reduction in number of drops reaching to the membrane surface is a function of the applied shear rate: increasing shear rate would reduce the number of reaching drop to the membrane surface. It is expected that rejection of drops through the membrane would be higher with the applied shear rate. As it is explained that migration velocities (shear-induced and inertial lift) is a function of drop size: higher the drop size higher would migration way from the surface of the membrane. So it can be seen (Fig. 8.) that $100 \%$ cut-off point decreased with the applied shear rate. At shear rate of $1200 \mathrm{~s}^{-1}$, the theory is not in agreement with the experiments due to the fact that $1200 \mathrm{~s}^{-1}$ is not a 
high shear rate and most of the drops reach to the surface of the membrane without effecting by the applied shear rate. Once the drops reach to the surface of the membrane than static force is responsible for the rejection of drops through the membrane, and that is the reason that $100 \%$ experimental cut-off without and with $1200 \mathrm{~s}^{-1}$ shear rate are nearly the same. A satisfactory agreement $\left(0,3200,8000 \mathrm{~s}^{-1}\right.$ shear rates) of our experimental data with the theory predictions show that the presented mathematical model can be applied for a prediction of the $100 \%$ cut-off with and without shear rate applying to the membrane.

Fig. 9. (a), (b) and (c) show $100 \%$ and below $100 \%$ rejections of crude oil droplets at various shear rates applied and at different flux rates used. It was found that rejection of droplets was the highest at the highest shear rate and was worse without a shear rate applied. It is clear that rejection of droplets decreased with increase of the filtration rate. $400 \mathrm{ppm}$ in the feed solution was reduced to $7 \mathrm{ppm}$ in the permeate with highest shear rate $\left(8000 \mathrm{~s}^{-1}\right)$ and the filtration rate of $200 \mathrm{I} \mathrm{m}^{-2} \mathrm{hr}^{-1}$. The latter is close to the $100 \%$ rejection in the agreement with the theory predictions. Table 1 shows that the higher the shear rate is the lower number of droplets was observed in the permeate.

\section{Conclusion}

Droplets moves at higher velocity to the membrane surface without shear rate applied as compared to velocity of droplets with applying shear rates. Lower velocity of droplets with shear rates is due to production of shear-enhanced diffusion and inertial lift force that acting in opposite direction to the filtration velocity. Migration velocity away from the surface of the membrane due to shear-enhanced migration and inertial lift forces is a function of the shear rate 
applied. Better rejection of the droplets occurred when shear rate was applied to the membrane. Rejection of droplets by the membrane increases linearly with the applied shear rates. At the highest shear rate used and the filtration velocity $200 \mathrm{I} \mathrm{m}^{-2} \mathrm{hr}^{-1}, 100 \%$ droplets rejection was predicted of droplets $3 \mu \mathrm{m}$ radius size. Experimentally we found that $400 \mathrm{ppm}$ of oil in the feed was reduced to $7 \mathrm{ppm}$ oil in the permeate, which is close to the $100 \%$ rejection predicted. The study presented in the paper can be applied on industrial scale for separation of crude oil droplets from Produced Water with the oscillation of the membrane for better separation.

\section{Acknowledgement}

Authors are very thankful to HEC Pakistan for providing funds for the project. V.Starov's research was supported by MUTIFLOW, EU grant. 


\section{References}

[1] J.H. Hargreaves, R.S. Silvester, Computational fluid dynamics applied to the analysis of de-oiling hydro-cyclone performance, Trans I Chem E 68 (1990) 365-383.

[2] S.R. Kosvintsev, P.D. Sutrisna, I.W. Cumming, R.G. Holdich, G. Mason, The passage of deforming oil drops through a slotted microfilter, Trans IChemE 85 (2007) 530-536.

[3] P.G. Grini, M. Hjelsvold, S. Johnsen, Statoil ASA, Trondheim, Choosing Produced Water Treatment Technologies Based on Environmental Impact Reduction, SPE 74 (2002) 1-11.

[4] S. Bednarski, J. Listewnik, Hydrocyclones for simultaneous removal of oil and solid particles from ship's oily waste, Filtration and Separation 25 (1988) 92-97.

[5] S.H. Lin, W.J. Lan, Waste oil/water treatment by membrane processes, J of Hazardous Materials 59 (1998) 189-199.

[6] P. Lipp, C.H. Lee, A.G. Fane, C.J.D. Fell, A fundamental study of ultrafiltration of oil-water emulsions, J Membrane Sci. 36 (1988) 161-177.

[7] A.B. Koltuniewicz, R.W. Field, T.C. Arnot, Cross-flow and mental study and analysis of flux decline, J Membrane Sci. 102 (1995) 193-207.

[8] A.B. Koltuniewicz, R.W. Field, Process factors during removal of oil-water emulsions with cross-flow microfiltration, Desalination 105 (1996) 79-89.

[9] J. Mueller, Y.W. Can, R.H. Davis, Crossflow microfiltration of oily water, J Membrane Sc. 129 (1997) 221-235. 
[10] P. Wang, N. Xu, J. Shi, A pilot study of the treatment of waste rolling emulsion using zirconia microfiltration membrane, J Membrane Sci. 173 (2000) 159-166.

[11] S.S. Madeni, M.K. Yeganeh, Microfiltration of emulsion oil waste water, J of Porous Materials 10 (2003) 131-138.

[12] R.G. Holdich, I.W. Cumming, I.D. Smith, Cross-flow micro-filtration of oil in water dispersions using surface filtration with imposed fluid rotation, $\mathrm{J}$ Membrane Sci. 143 (1998) 263-274.

[13] A.J. Bromley, R.G. Holdich, I.W. Cumming, Particulate fouling of surface microfilters with slotted and circular pore geometry, J Membrane Sci. 196 (2002) 27-37.

[14] I.W. Cumming, R.G. Holdich, I.D. Smith, The rejection of oil by microfiltration of a stabilised kerosene/water emulsion, J Membrane Sci. 169 (2000) 147-155.

[15] H.J. Keh, Y. Chen Po, slow motion of a droplet between two parallel walls, Chem Eng Sci 56 (2001) 6863-6871.

[16] D.J. McClements Food Emulsions: Principles, Practice and Techniques. CRC Press (1999) 378 pages.

[17] I. W. Cumming R. G. Holdich, I. D. Smith, The rejection of oil using an asymmetric metal microfilter to separate an oil in water dispersion, Wat. Res. 33 (1999) 3587-3594.

[18] M.Y. Jaffrin, Dynamic shear-enhanced membrane filtration: A review of rotating disks, rotating membranes and vibrating systems, J Membrane Sci. 324 (2008) 7-25. 
[19] J. Postlethwaite, S.R. Lamping, G.C. Leach, M.F. Hurwitz, G.J. Lye, Flux and transmission characteristics of a vibration microfiltration system operated at high biomass loading, J Membrane Sci. 228 (2004) 89-101.

[20] O.A. Akoum, M.Y. Jaffrin, L. Ding, P. Paullier, C. Vanhoutte, An hydrodynamic investigation of microfiltration and ultrafiltration in a vibrating membrane module, J Membrane Sci. 197 (2002) 37-52.

[21] A.Ullah, V.M. Starov, M. Naeem, R.G. Holdich, Microfiltration of deforming oil droplets on a slotted pore membrane and sustainable flux rates, J Membrane Sci. 382 (2011) 271-277.

[22] S.P. Beier, M. Guerra, A. Garde, G. Jonsson, Dynamic microfiltration with a vibrating hollow fiber membrane module: filtration of yeast suspensions, $\mathrm{J}$ Membrane Sci. 281 (2006) 281-287.

[23] H.G. Gomaa, S. Rao, Analysis of flux enhancement at oscillating flat surface membranes, J Membrane Sci. 374 (2011) 59-66.

[24] A. Ullah, R.G. Holdich, M. Naeem, V.M. Starov, Stability and deformation of oil drops during microfiltration on a slotted pore membrane, J Membrane Sci $x x x(2012), x x x-x x x$.

[25] H.J. Keh, Y. Chen Po, slow motion of a droplet between two parallel walls, Chem Eng Sci 56 (2001) 6863-6871.

[26] S.D. Hudson, Wall migration and shear-induced diffusion of fluid droplets in emulsion, AIP Physics of Fluids, 15 (2003), 1106-1113.

[27] G. Belford, R.D. Davis, A.L. Zydney, The behavior of suspensions and macromolecular solutions in crossflow microfiltration, J Membrane Sci. 96 (1994), 1-58. 
[28] J. A. Schonberg, E.J. Hinch, Inertial migration of a sphere in Poiseuille flow, J Fluid Mech. 203 (1989), 517-524.

[29] S.P. Beier, M. Guerra, A. Grade, G. Jonsson, Dynamics microfiltration with a vibrating hollow fibre membrane module: Filtration of yeast suspensions, J. Membr. Sci. 281 (2006) 281-287.

[30] H.G. Gomaa, S. Rao, Analysis of flux enhancement at oscillating flat surface membrane, J Membrane Sci. 374 (2011), 59-66. 


\section{List of Figures}

Fig. 1. Schematic view of deforming droplets at equilibrium position.

Fig. 2. 1- rejection curve when the shear rate is not applied. 2- calculations according to the described above procedure of the rejection.

Fig. 3. Image of the surface of a slotted pore membrane.

Fig. 4. Schematic view of vibrating microfiltration rig.

Fig. 5. Typical size distribution (Cumulative mass undersized "m" VS droplet diameter "d") of the crude oil droplets $\left(22^{\circ} \mathrm{API}\right)$.

Fig. 6. Predicted drops size that would not reach to the surface of the membrane due to migration velocities created by the applied shear rate.

Fig. 7. Rejection (\%) against velocity $(\mathrm{m} / \mathrm{s})$ of droplets taking $2 \mu \mathrm{m}$ as a reference droplet, at various shear rates.

Fig. 8. Experimental measurements and theoretical points of $100 \%$ cut-off during filtering crude oil droplets $\left(22^{\circ} \mathrm{A}\right)$ at various shear rates $(0,1200,3200$, $\left.8000 \mathrm{~s}^{-1}\right)$ with different flux rates $\left(200,400\right.$ and $\left.600 \mathrm{I} \mathrm{m}^{-2} \mathrm{hr}^{-1}\right)$.

Fig. 9. (a) Rejection of crude oil droplets at flux rate $\left(200 \mathrm{I} \mathrm{m}^{-2} \mathrm{hr}^{-1}\right)$ and various shear rates $\left(0,1200,3200,8000 \mathrm{~s}^{-1}\right)$.

Fig. 9. (b) Rejection of crude oil droplets $\left(22^{\circ} \mathrm{A}\right)$ at flux rate $\left(400 \mathrm{I} \mathrm{m}^{-2} \mathrm{hr}^{-1}\right)$ and various shear rates $\left(0,1200,3200,8000 \mathrm{~s}^{-1}\right)$.

Fig. 9. (c) Rejection of crude oil droplets at flux rate $\left(600 \mathrm{I} \mathrm{m}^{-2} \mathrm{hr}^{-1}\right)$ and various shear rates $\left(0,1200,3200,8000 \mathrm{~s}^{-1}\right)$. 
Table 1 Number of crude oil drops and concentration of oil in the feed and permeate obtained at various shear rates and $200 \mathrm{I} \mathrm{m}^{-2} \mathrm{hr}^{-1}$ flux rate.

\begin{tabular}{|c|c|c|c|}
\hline Shear rate $\left.\mathbf{s}^{-1}\right)$ & $\begin{array}{c}\text { No of Droplets in } \\
\text { the permeate per } \\
\text { 0.4 } \mathbf{m l} \text { sample }\end{array}$ & $\begin{array}{c}\text { Concentration of crude } \\
\text { oil in the feed } \\
\text { (ppm) }\end{array}$ & $\begin{array}{c}\text { Concentration of crude } \\
\text { oil in the permeate } \\
\text { (ppm) }\end{array}$ \\
\hline 8000 & 1606 & 400 & 7 \\
\hline 3200 & 2162 & 400 & 10 \\
\hline 1200 & 3247 & 400 & 14 \\
\hline 0 & 5092 & 400 & 16 \\
\hline
\end{tabular}




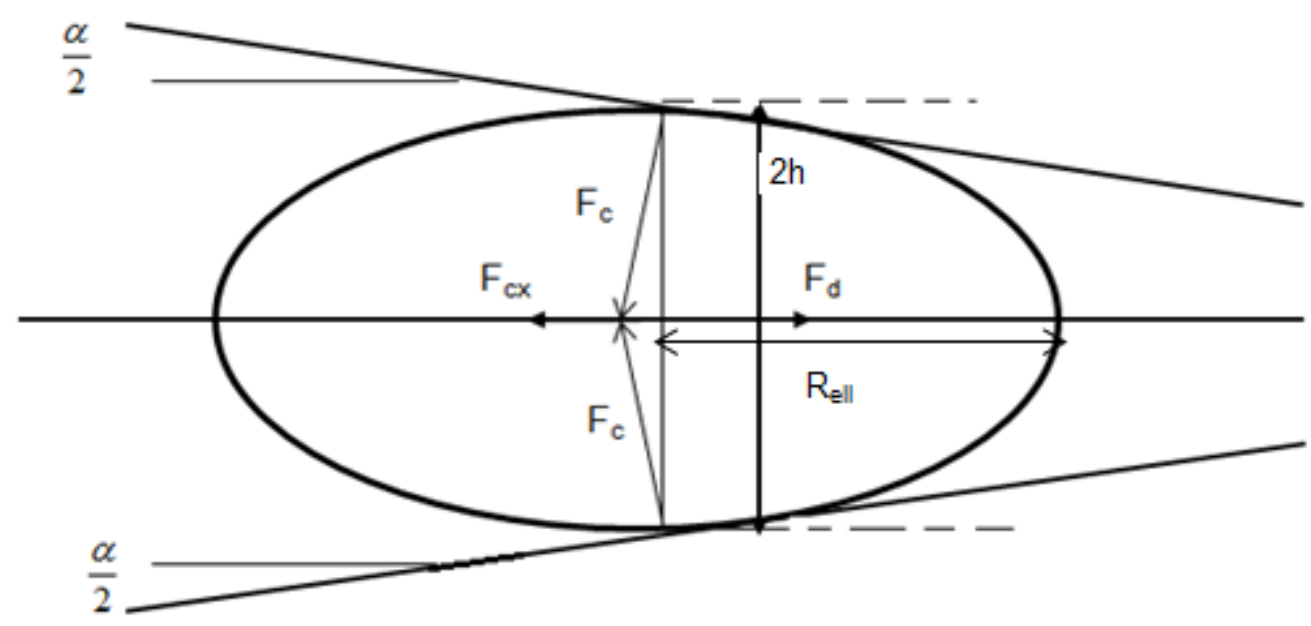

Fig. 1. Schematic view of deforming droplets at equilibrium position. 


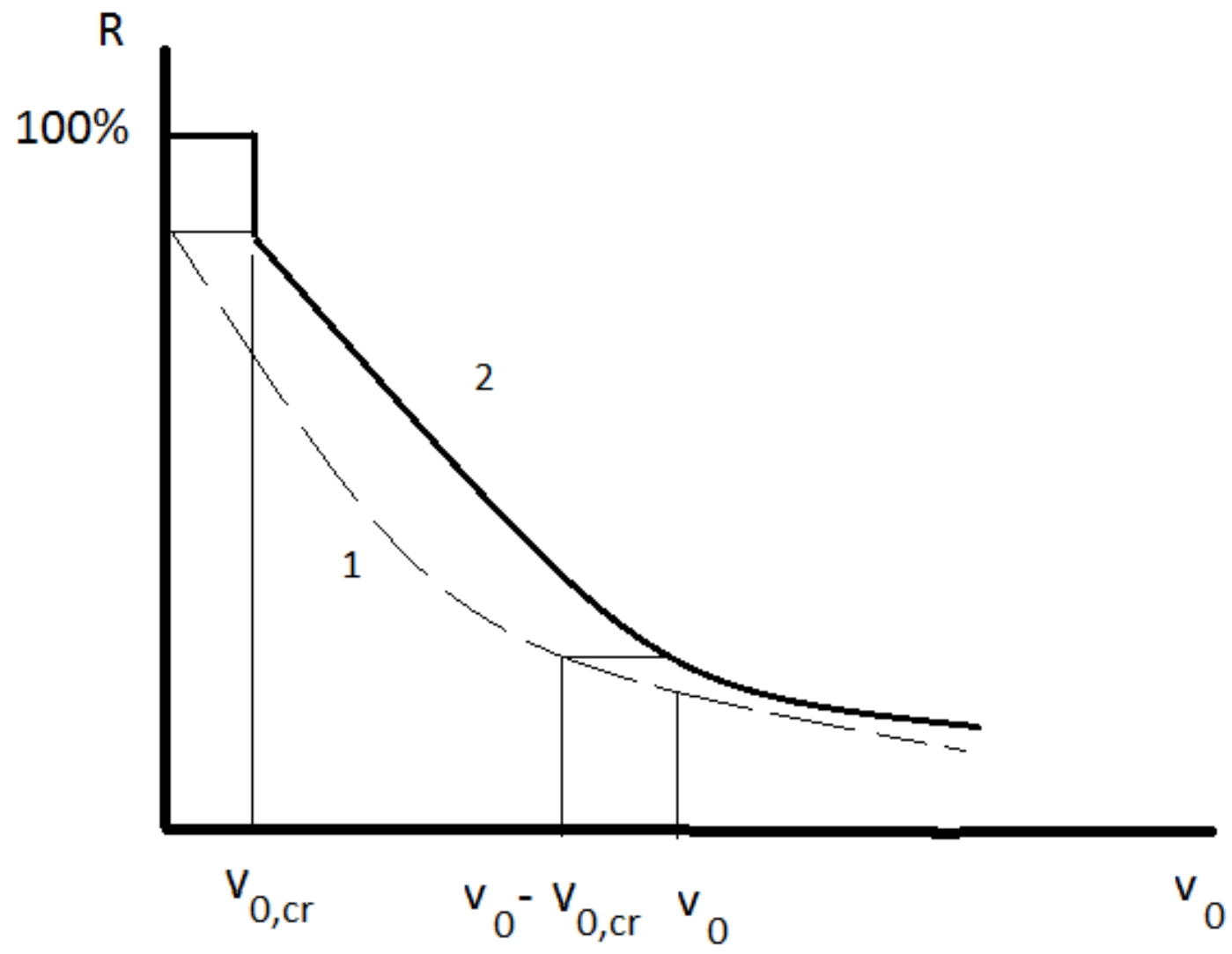

Fig. 2. 1- rejection curve when the shear rate is not applied. 2- calculations of the rejection according to the described procedure (see text). 


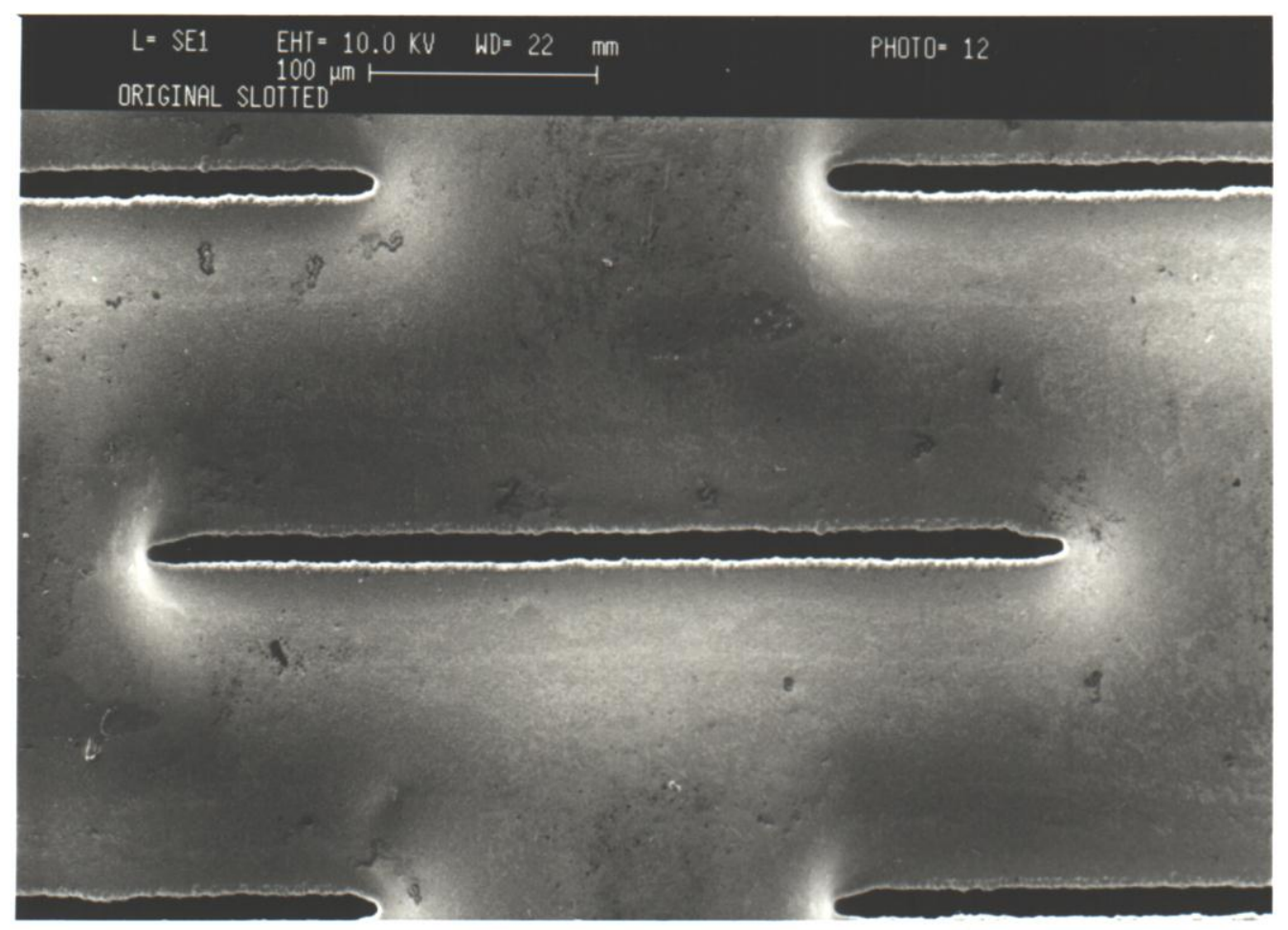

Fig. 3. Image of the surface of a slotted pore membrane. 


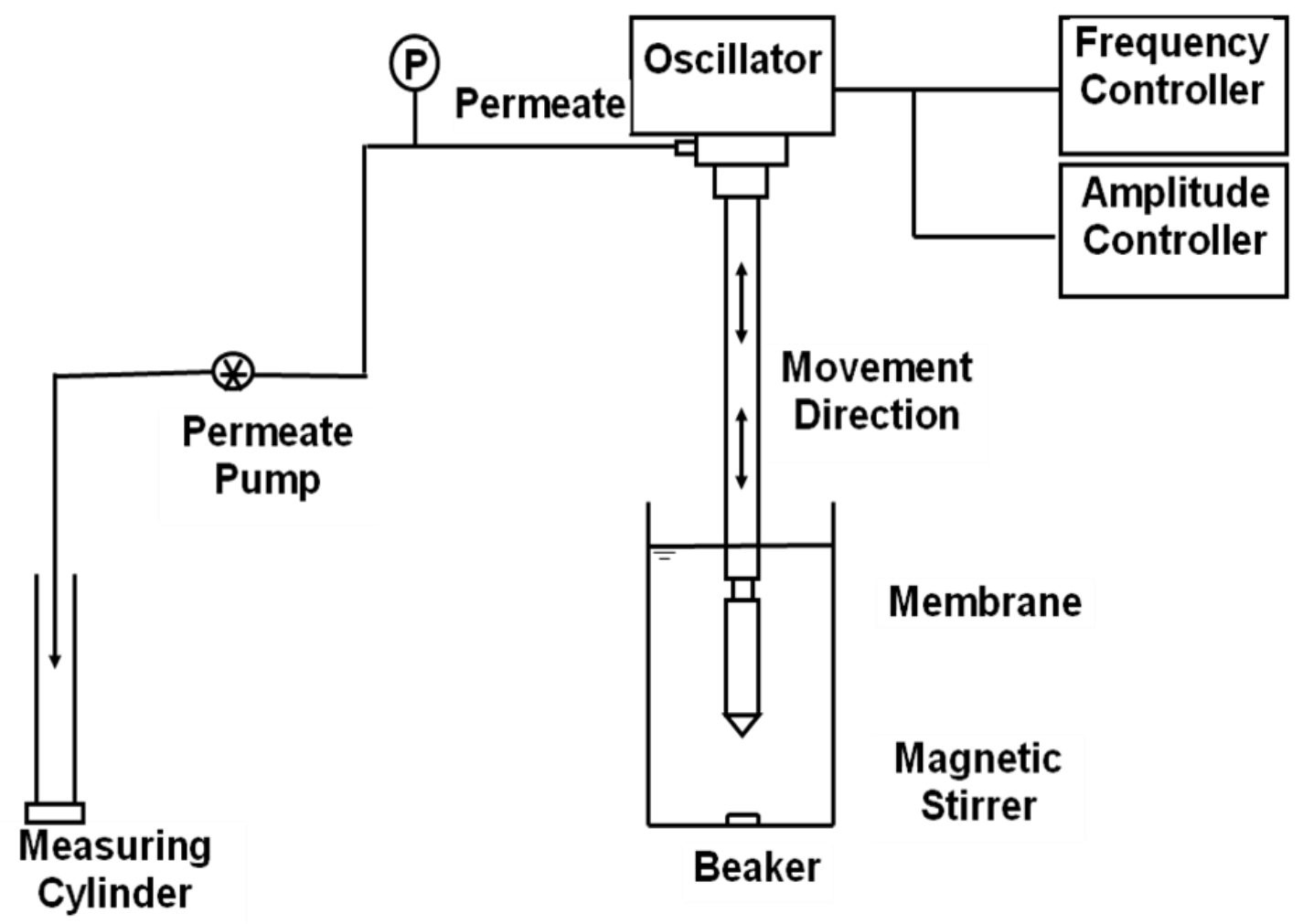

Fig. 4. Schematic view of vibrating microfiltration rig 


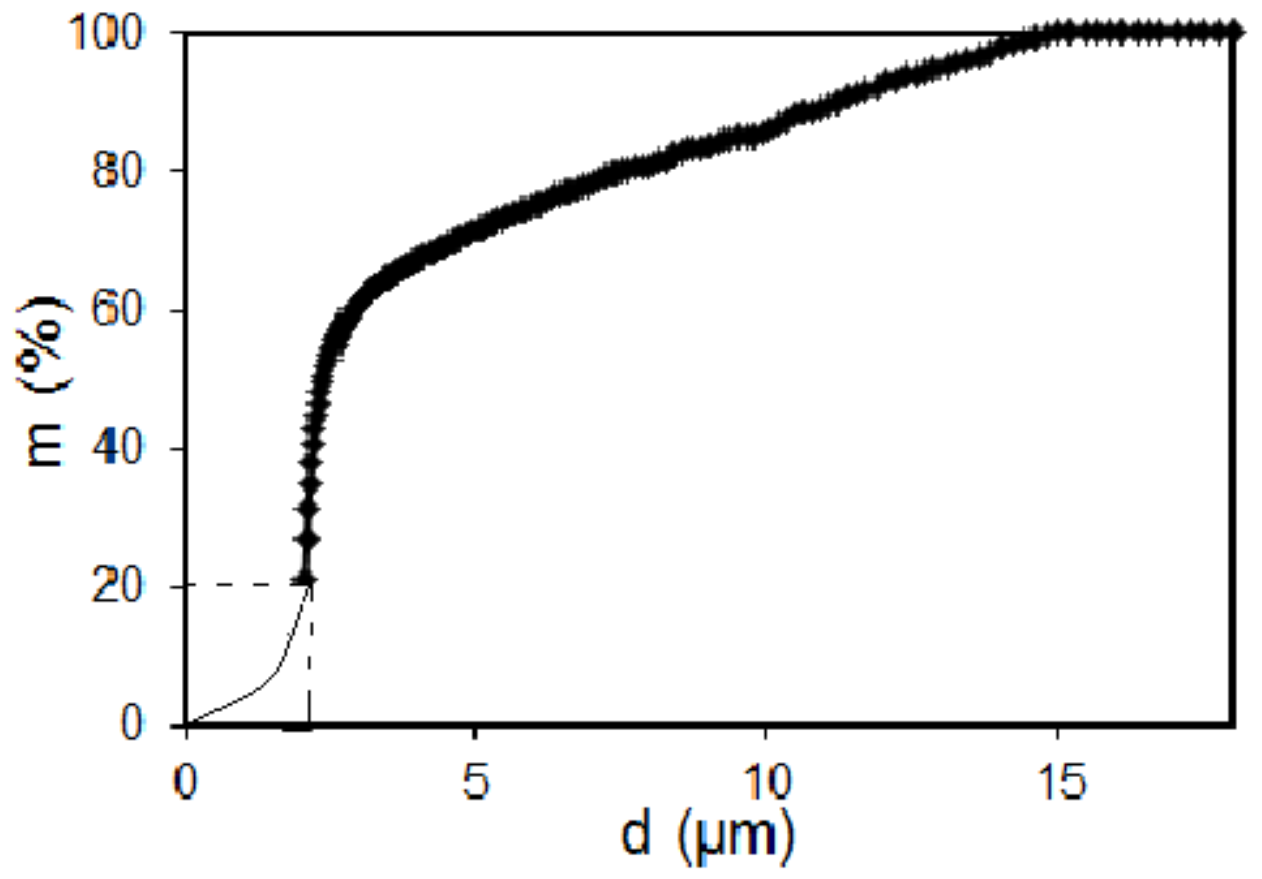

Fig. 5. Typical size distribution (Cumulative mass undersized "m" against droplet diameter "d") of the crude oil droplets $\left(22^{\circ} \mathrm{API}\right)$. 


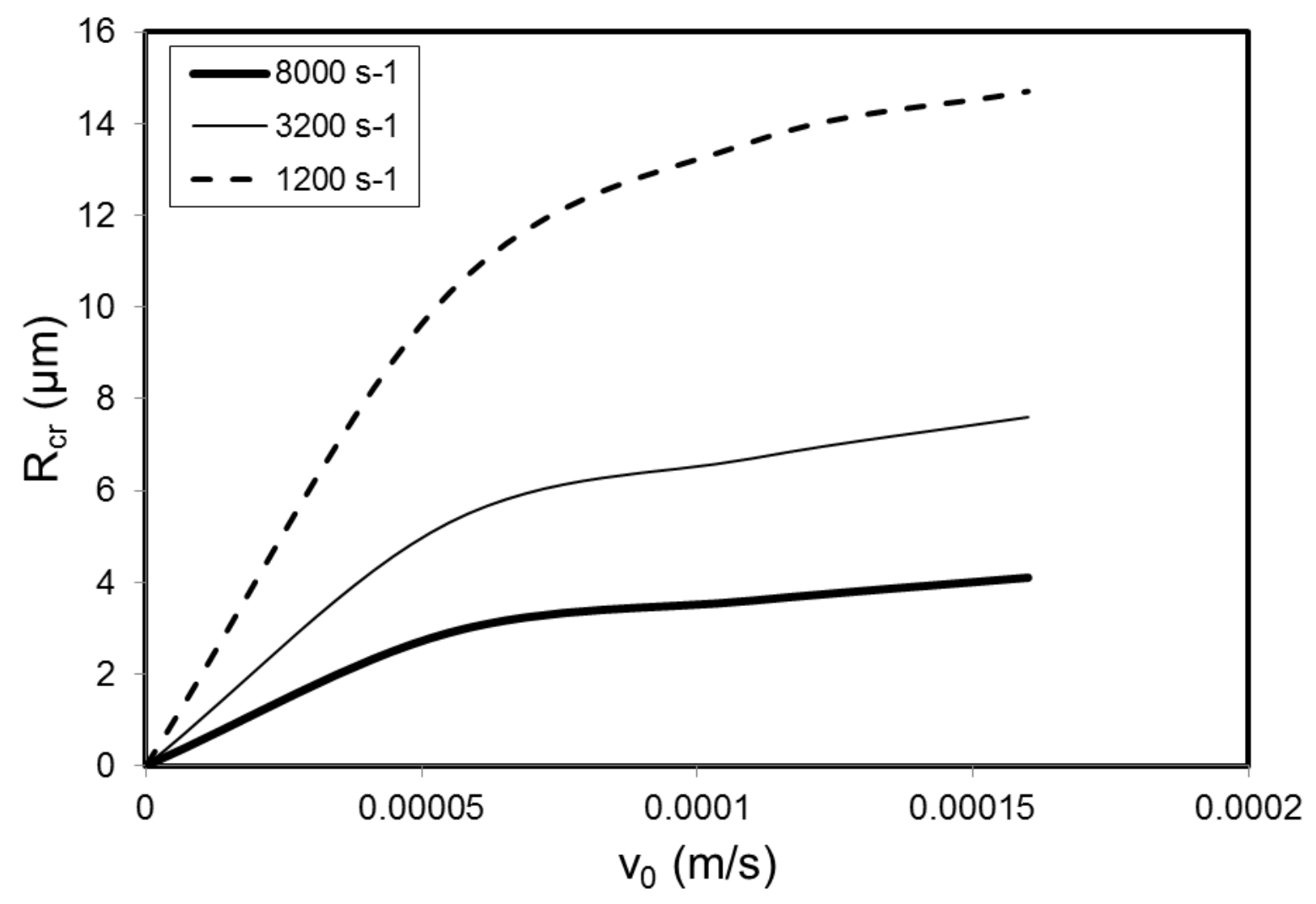

Fig. 6. Predicted drop size that would not reach the surface of the membrane due to migration velocities created by the fixed applied shear rate according to Eq (8). 


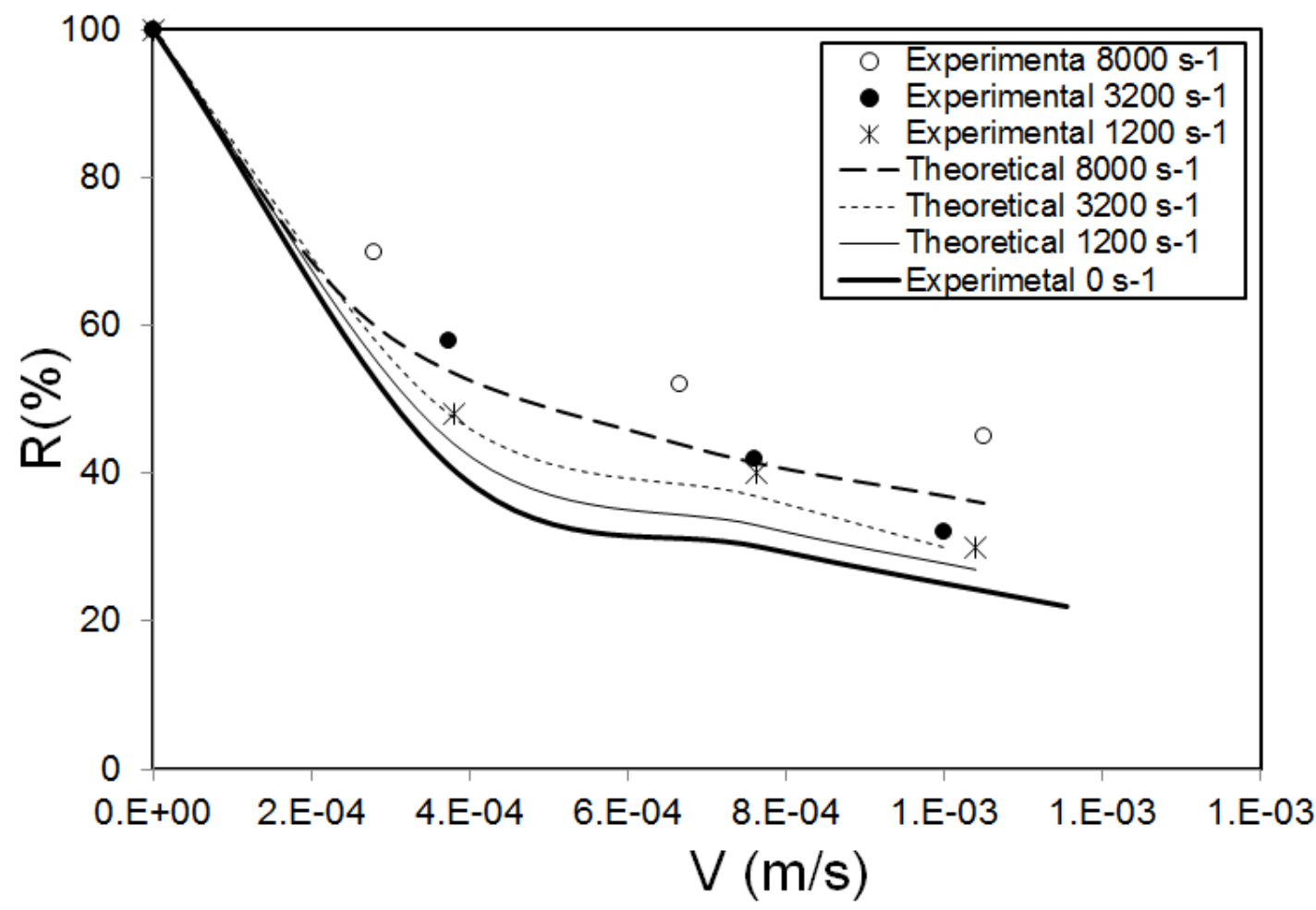

Fig. 7. Rejection (\%) against filtration velocity $(\mathrm{m} / \mathrm{s})$ of $2 \mu \mathrm{m}$ droplets at various shear rates according to the procedure presented in Fig. 2 . 


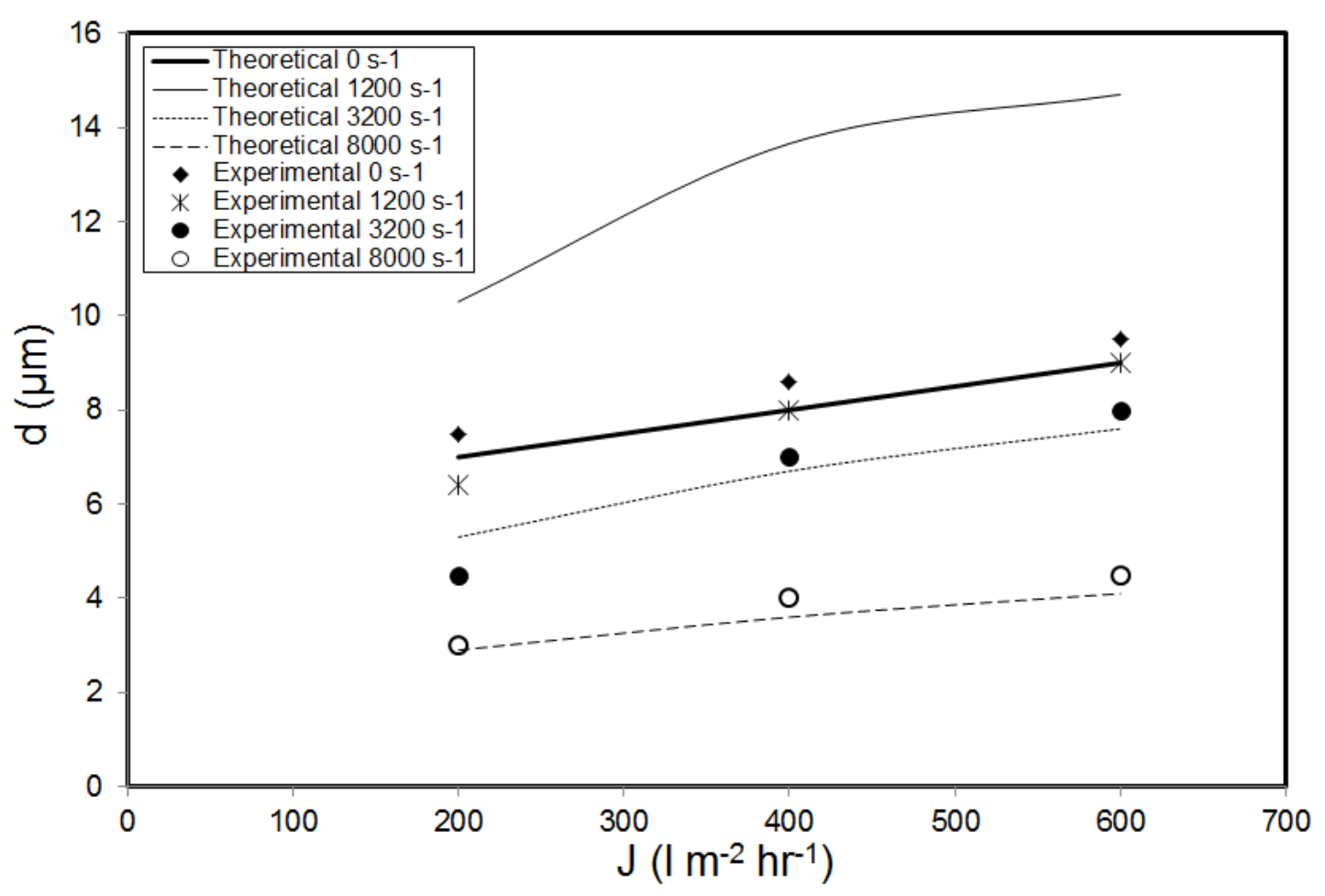

Fig. 8. Experimental measurements and theoretical points of $100 \%$ cut-off during filtering of crude oil droplets $\left(22^{\circ} \mathrm{A}\right)$ at various shear rates $(0,1200$, $\left.3200,8000 \mathrm{~s}^{-1}\right)$ with different flux rates $\left(200,400\right.$ and $\left.600 \mathrm{I} \mathrm{m}^{-2} \mathrm{hr}^{-1}\right)$. 


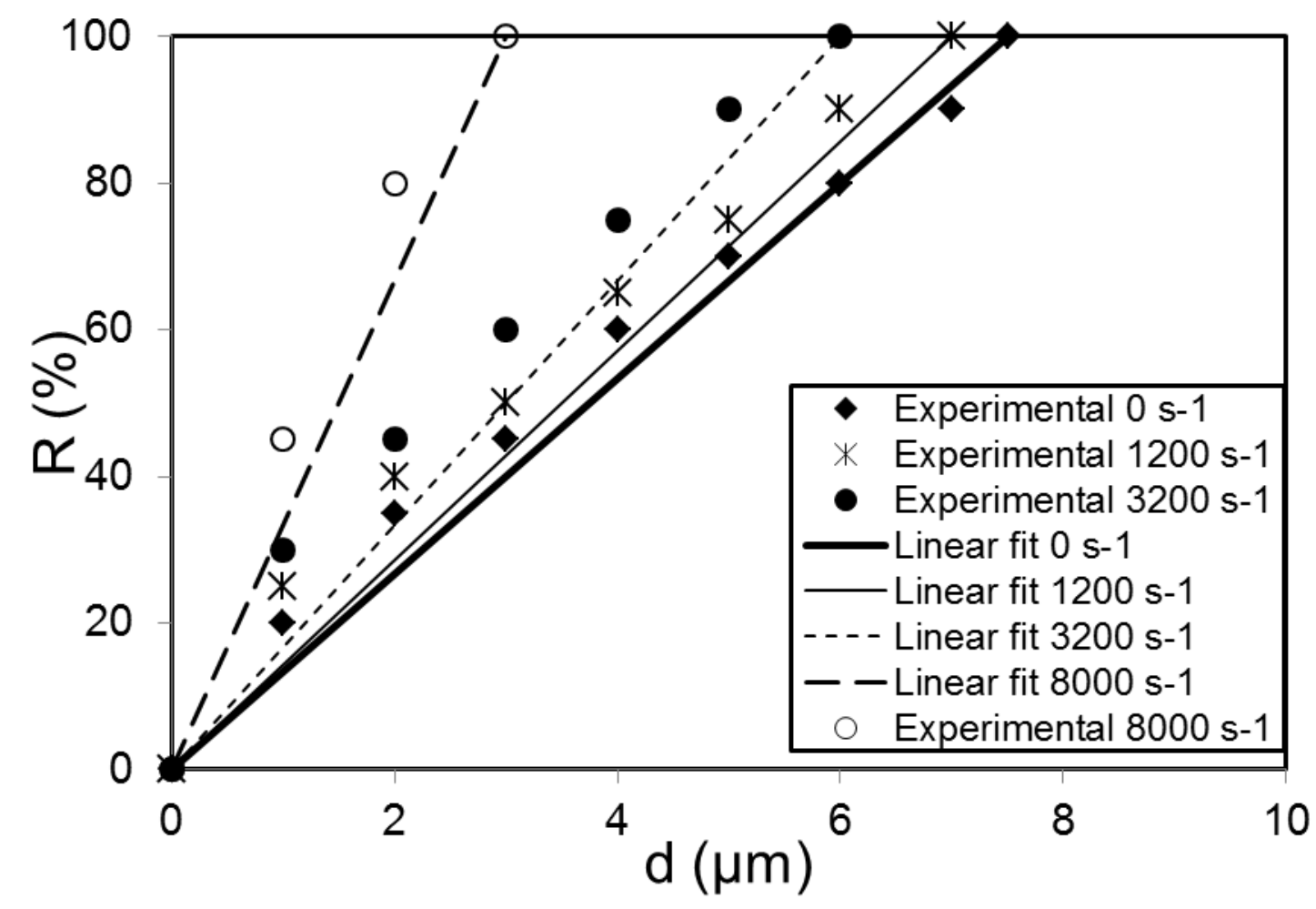

Fig. 9. (a) Rejection of crude oil droplets at flux rate $\left(200 \mathrm{I} \mathrm{m}^{-2} \mathrm{hr}^{-1}\right)$ and various shear rates $\left(0,1200,3200,8000 \mathrm{~s}^{-1}\right)$. 


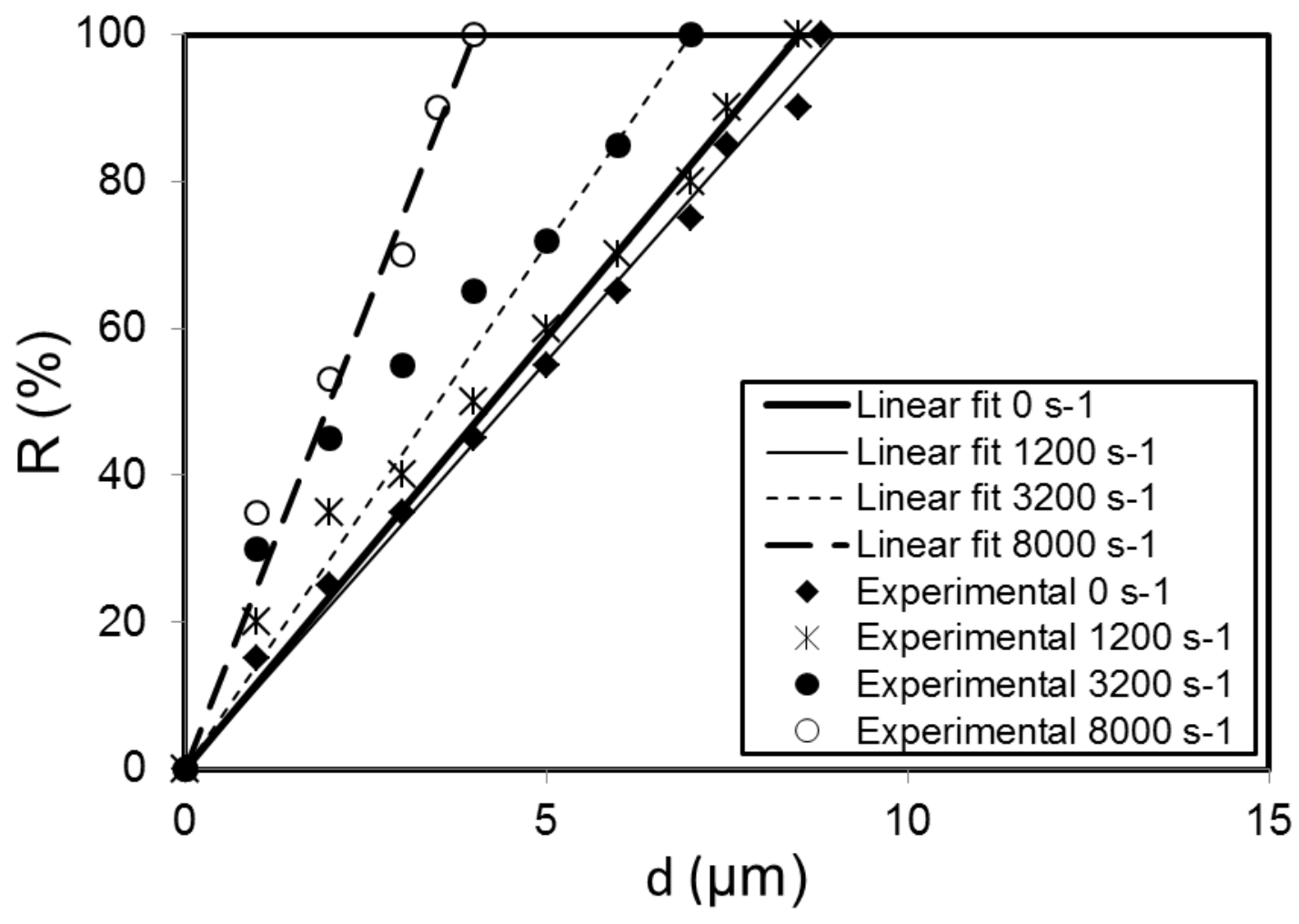

Fig. 9. (b) Rejection of crude oil droplets $\left(22^{\circ} \mathrm{A}\right)$ at flux rate $\left(400 \mathrm{I} \mathrm{m}^{-2} \mathrm{hr}^{-1}\right)$ and various shear rates $\left(0,1200,3200,8000 \mathrm{~s}^{-1}\right)$. 


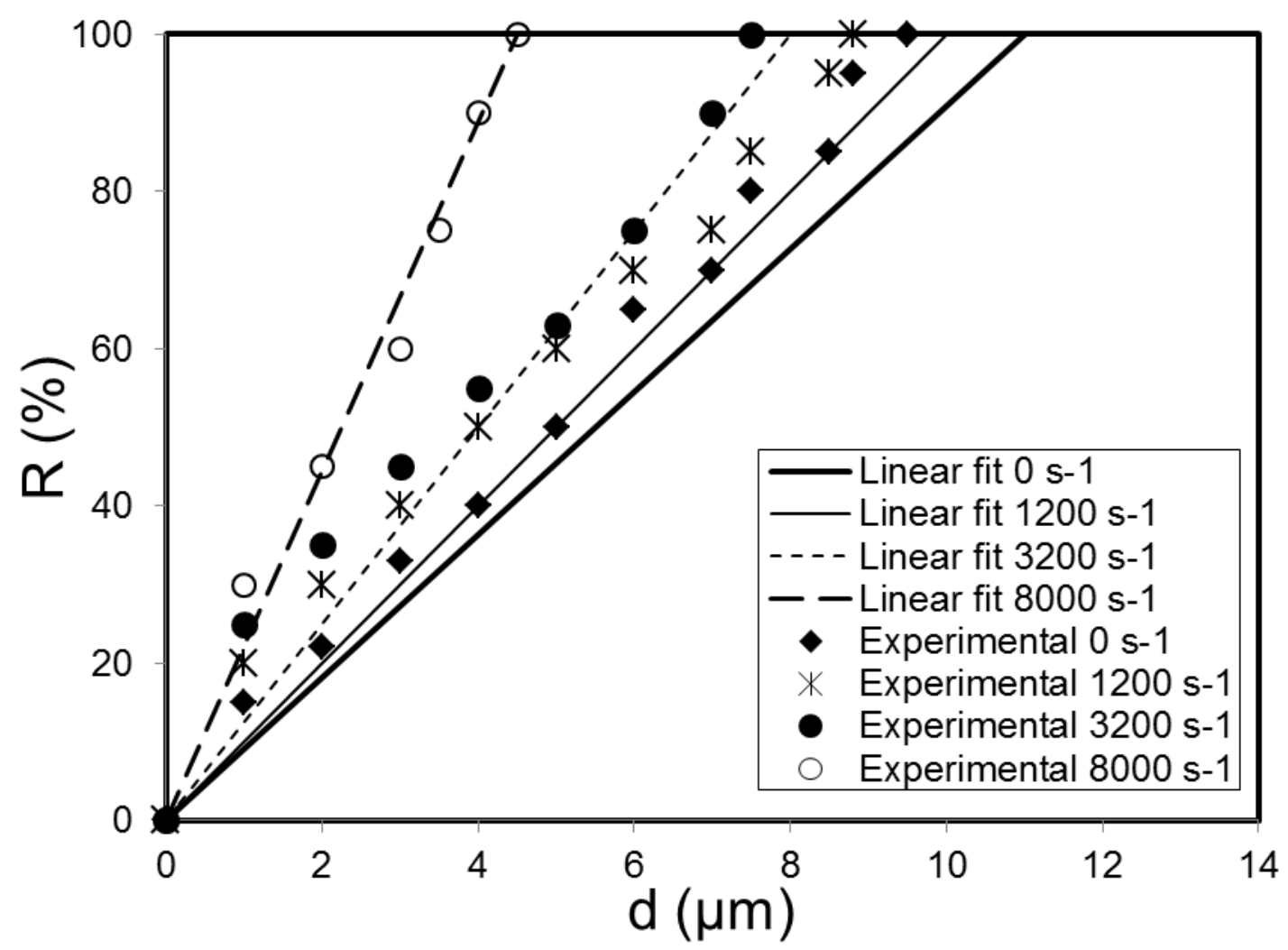

Fig. 9. (c) Rejection of crude oil droplets at flux rate $\left(600 \mathrm{I} \mathrm{m}^{-2} \mathrm{hr}^{-1}\right)$ and various shear rates $\left(0,1200,3200,8000 \mathrm{~s}^{-1}\right)$. 